ISSN: 2638-5945

\title{
Central Nervous System Manifestation of Multiple Myeloma: A Case Report
}

\author{
Dinesh Singh*, Prekshi Chowdhary, Swati and Gopal S \\ Department of Radiation Oncology, Max Super Speciality, Vaishali, Ghaziabad, India
}

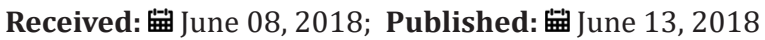

*Corresponding author: Dinesh Singh, Department of Radiation Oncology, Max Super Speciality, Vaishali, Ghaziabad, Uttar Pradesh, India

\begin{abstract}
Multiple myeloma accounts for $<1 \%$ of all malignancies and Central nervous system (CNS) manifestation of multiple myeloma $(\mathrm{MM})$ is rare. Multiple myelomais characterized by malignant transformation of plasma cells that produces immunoglobulin chains. The accumulation of plasma cells in bone marrow results in clinical features like anaemia, osteolytic lesions, hypocalcaemia, renal failure and immunodeficiency [1,2]. The involvement of central nervous system is very uncommon in multiple myeloma and it may present early or late during the course of disease. The neurological symptoms can be diffuse headache, persistent vomiting, vertigo, weakness in limbs, urinary incontinence etc. Symptoms can be attributed to spinal cord or nerve root compression, peripheral neuropathies, and uremia [3,4]. Likely risk factors of CNS manifestation are unfavourable cytogenetics, high tumour load, low marrow involvement. In this report we describe a patient with CNS involvement after receiving systemic chemotherapy and symptomatic treatment.
\end{abstract}

Keywords: Central nervous system; Multiple myeloma

\section{Case Report}

A 52 years pleasant lady presented with complaint of pain in left leg with lower backache and tingling sensations for 10 days. Subsequently she developed pain in right leg followed by urine incontinence. MRI Lumbosacral Spine was done which reported ill defined lesions at L3-L4 vertebra (with associated periosseous fluid collections) and multiple focal lesions in the L4 vertebra, bilateral sacral ala and both iliac bones along with indentations upon the thecal sac by spondyliticridges, secondary spinal canal stenosis and neural foraminal narrowing at multiple levels and left exiting nerve root compression at L3-L4, L5-S1 levels (Table 1). She underwent L1-L5 stabilization, L3 decompression with laminectomy, biopsy, posterolateral fusion with local autograft. Histopathology reported plasma cell dyscrasia at L3-L4 level. Immunohistochemistry reported tumor cells are focally positive for CD-138 and kappa light chain and negative for lambda light chain. On further evaluation bone marrow biopsy reported plasma cells approximately $50 \%$ of total nucleated cells suggestive of plasma cell myeloma. Bone marrow aspiration shows plasmacytosis approximately $24 \%$ of total nucleated cells which confirmed the diagnosis. She received 15 cycles of Bortezomib and Thalidomide.
Table 1.

\begin{tabular}{|c|c|}
\hline \multicolumn{2}{|c|}{ CBC } \\
\hline $\mathrm{Hb}$ & $10.5 \mathrm{~g} / \mathrm{dl}$ \\
\hline TLC & 13.5 thou/ul \\
\hline Platelets count & 305 thou/ul \\
\hline Serum total protein & $9.47 \mathrm{gm} / \mathrm{dl}$ \\
\hline Serum albumin & $3.21 \mathrm{~g} / \mathrm{dl}$ \\
\hline Serum globulin & $6.26 \mathrm{~g} / \mathrm{dl}$ \\
\hline Albumin/globulin ratio & 0.51 \\
\hline \multicolumn{2}{|c|}{ KFT } \\
\hline Serum creatinine & $1.24 \mathrm{mg} / \mathrm{dl}$ \\
\hline Serum Calcium & $8.44 \mathrm{mg} / \mathrm{dl}$ \\
\hline
\end{tabular}

Table 2.

\begin{tabular}{|c|c|}
\hline Serum protein electrophoresis & Result \\
\hline Serum protein & $5.50 \mathrm{~g} / \mathrm{dl}$ \\
\hline Serum albumin & $2.88 \mathrm{~g} / \mathrm{dl}$ \\
\hline Beta 2 Microglobulin & $2371 \mathrm{mcg} / \mathrm{ml}$ \\
\hline
\end{tabular}




\begin{tabular}{|c|c|}
\hline M-spike & $0.13 \mathrm{~g} / \mathrm{dl}$ \\
\hline \multicolumn{2}{|c|}{ Immunoglobulin } \\
\hline IgG & $557 \mathrm{mg} / \mathrm{dl}$ \\
\hline IgM & $43.0 \mathrm{mg} / \mathrm{dl}$ \\
\hline Kappa Free Light chain & $22.0 \mathrm{mg} / \mathrm{dl}$ \\
\hline Lambda, free light chain & $335.0 \mathrm{mg} / \mathrm{L}$ \\
\hline Kappa/Lambda ratio & $4.96 \mathrm{mg} / \mathrm{L}$ \\
\hline LDH & 67.540 \\
\hline Hb & 875.0 \\
\hline TLC & \\
\hline Platelet & $9.7 \mathrm{gm} / \mathrm{dl}$ \\
\hline
\end{tabular}

cyclophosphamide and dexamethasone. After few days, she developed headache, giddiness and syncopal attacks. On evaluation CEMRI brain reported diffuse leptomeningeal enhancement involving both cerebral as well as cerebellar hemispheres. Mild enhancement of basal cistern with associated marginal dilation of ventricular system (Figure 1). In view of above mentioned complaints, cerebrospinal fluid study was done (Table 3) (Figure 2). CEMRI spine was done which reported no abnormal enhancement in vertebra, cord or thecal sac (Figures $3 \& 4$ ). She received 7 fractions (14 Gy) out of 12 planned fractions (24Gy) of whole brain radiotherapy and two intra thecal injection of methotrexate. MRI upper abdomen with MRCP reported large mass replacing entire head and body region of pancreas. Mass encases and compresses CBD with mild bilobar intra hepatic biliary radical dilation. There is also encasement of second part of duodenum with possible infiltrartion of adjacent hepatic parenchyma as well. Features are suggestive of aggressive pancreatic malignanacy, possibility of pancreatic lymphoma. Thickening and edema of gall bladder wall was seen which was suggestive of concomitant cholecystitis. She was advised for ERCP with SEMS placement which was refused by attendants (Figure 5). In view of her deranged liver function test, both radiotherapy and methotrexate were discontinued and she was maintained on supportive care (Table 4). Whole body PET CT reported metabolically active soft mass lesion in gastro hepatic region measuring $9.7 \times 5.5 \mathrm{~cm}$ SUV max 20.3, recto uterine pouch measuring $9.2 \times 7.8 \mathrm{~cm}$ SUV 20.9, left iliac fossa measuring $7.2 \times 4.0 \mathrm{~cm}$ - ?mitotic, metabolically active mesenteric nodes measuring upto $2.2 \mathrm{~cm}-$ ? mitotic and metabolically active lytic lesion involving L3 vertebra with paravertebral soft tissue component infiltrating left psoas muscles.

Table 3.

\begin{tabular}{|c|c|}
\hline $\begin{array}{c}\text { CSF- Cell type } \boldsymbol{\&} \text { Count, Glucose, } \\
\text { Protein }\end{array}$ & Result \\
\hline Colour & Colourless \\
\hline Appearance & Clear \\
\hline CSF Glucose & $41 \mathrm{mg} / \mathrm{dl}$ \\
\hline CSF Protein & $105 \mathrm{mg} / \mathrm{dl}$ \\
\hline CSF TLC & 580 cells $/$ cumm \\
\hline Microscopic examination & \\
\hline Plasma cells & $100 \%$ \\
\hline
\end{tabular}

Table 4.

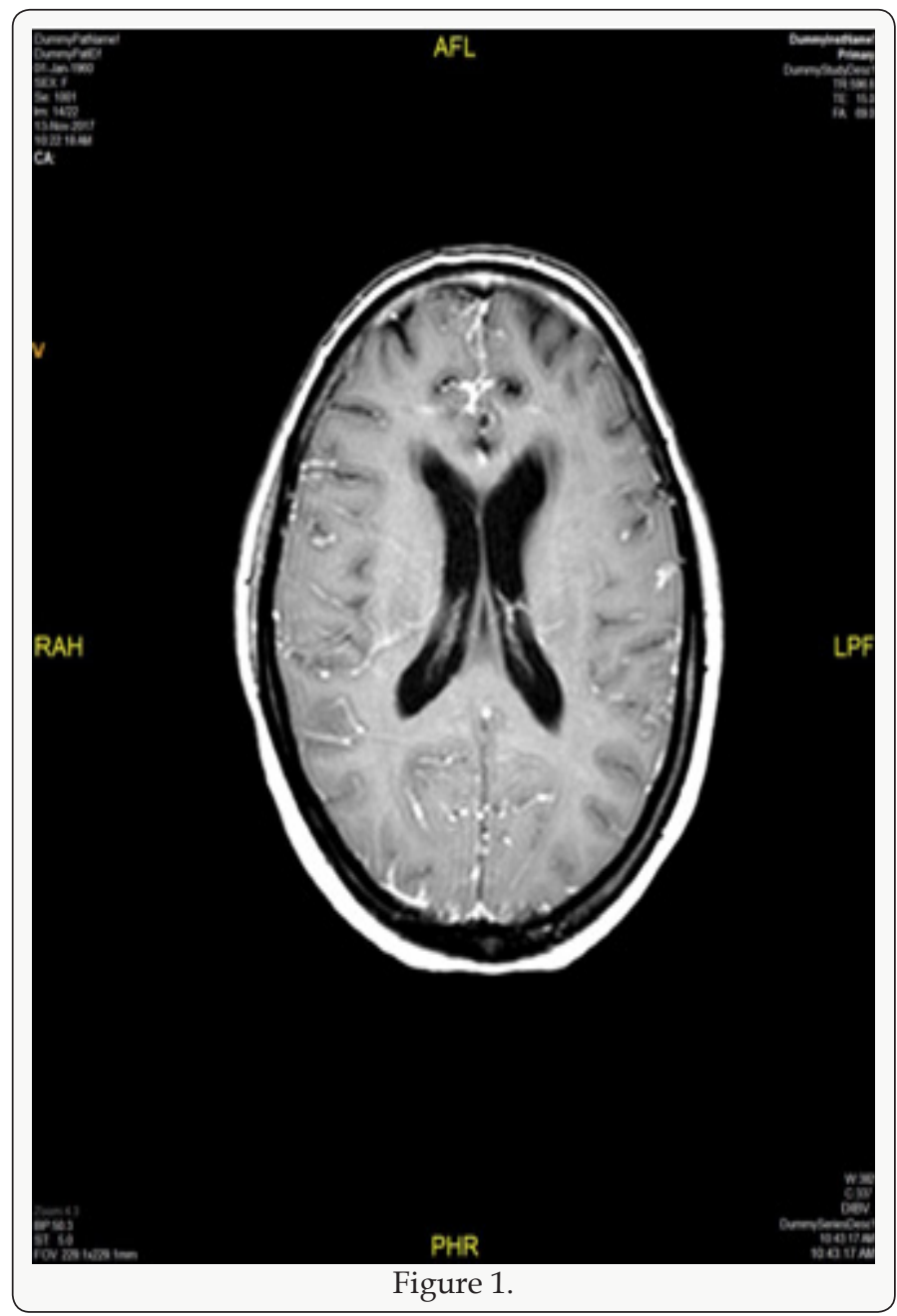



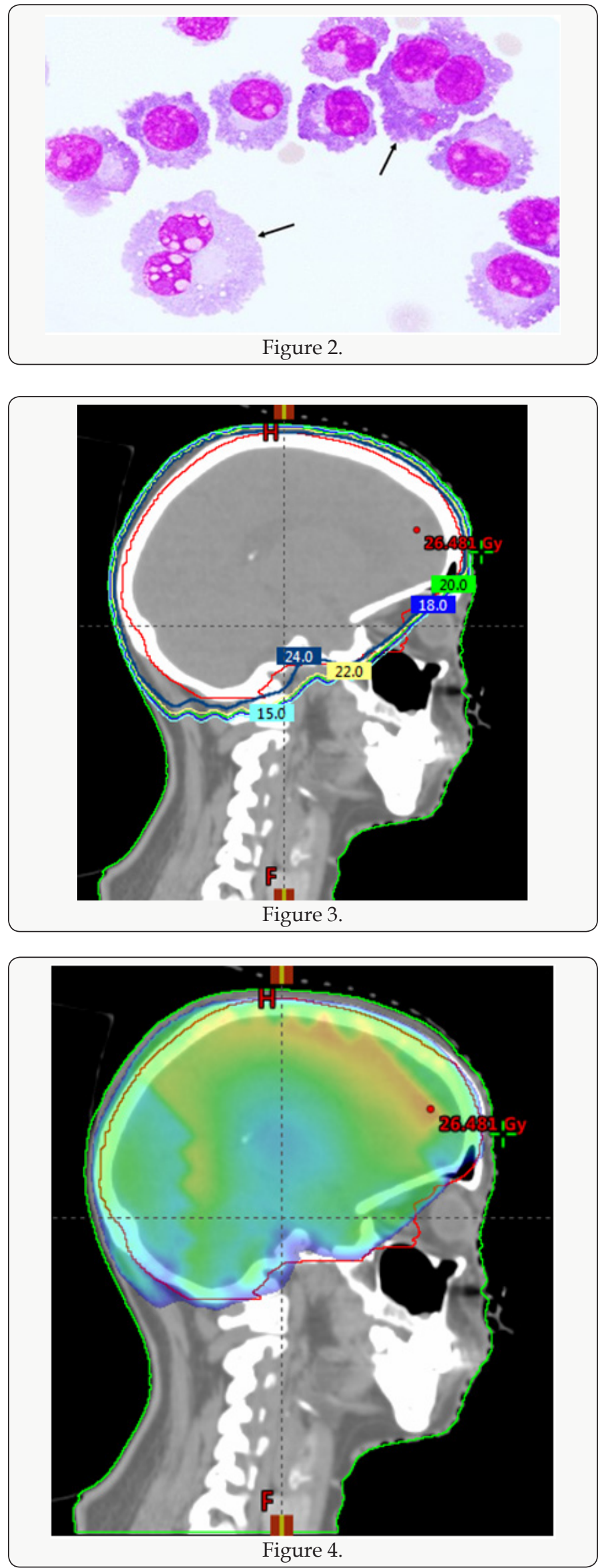

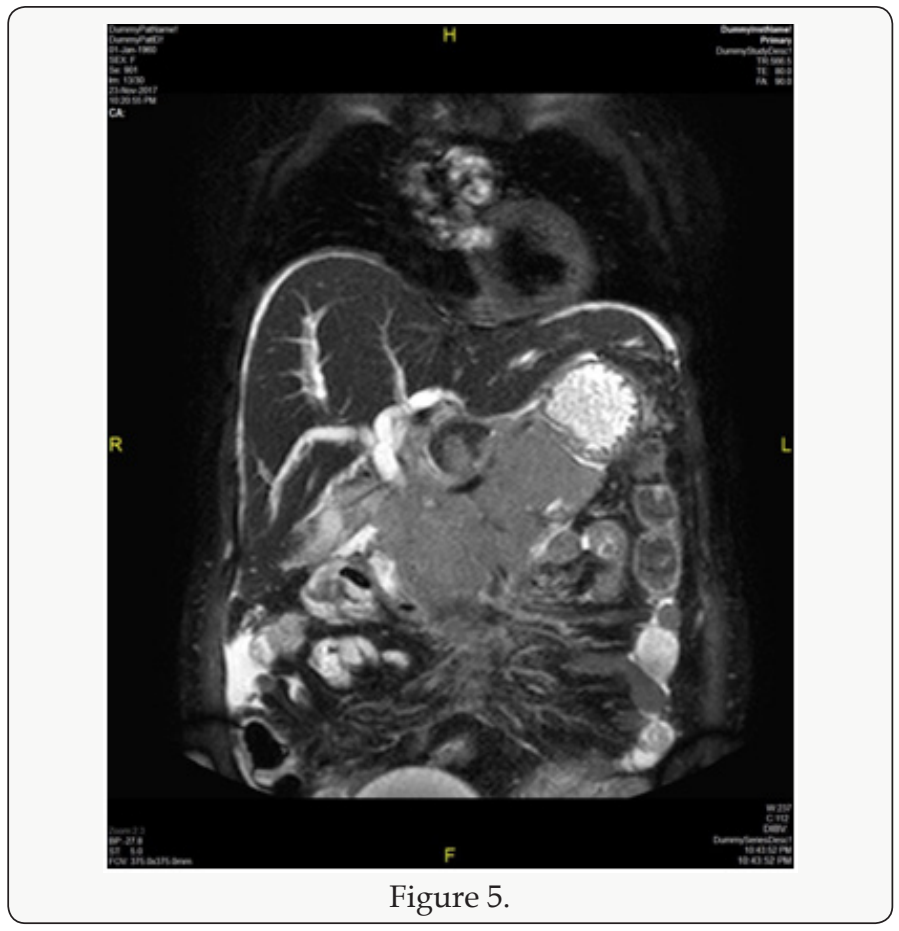

\section{Discussion}

Central nervous system is a rare location of involvement in MM, however it should be considered if a patient with MM presents with neurologic symptoms. Patients with MM often have neurological complications, either due to metabolic disorders such as hypocalcaemia, uraemia and hyper viscosity or due to peripheral neuropathy, spinal cord compression and cranial nerve infiltration $[1,2]$. The most common cause is spinal cord compression and cranial nerve infiltration $[3,4]$. The patient may present as a known case of MM with CNS features or as a new case with CNS symptoms. The clinical presentation depends on degree and site of infiltration. The symptoms and signs are headache, memory loss, behavioural changes, convulsions, nausea, vomiting, vertigo, urinary incontinence, backache, and limb weakness $[3,4]$. These symptoms can be attributed to spinal cord or nerve root compression, raised intracranial tension, meningeal inflammation [5]. In our case she presented with the complaint of headache, giddiness and syncopal attacks. This can be explained by CEMRI brain imaging which reported diffuse leptomeningeal enhancement involving both cerebral as well as cerebellar hemispheres. CSF study was done to reported to be negative. She received 7 fractions out of 12 fractions planned for whole brain radiotherapy and two injections of intrathecal Methotrexate injections [6]. In view of deranged LFT, radiotherapy and IT chemotherapy was stopped and was managed conservatively. She passed away after 2 weeks due to sepsis with LRTI with MM as underlying cause.

\section{Conclusion}

In conclusion this patient had an aggressive disease in view of abdominal deposits and unresponsiveness to multiple lines 
of systemic disease. CNS involvement in cases of MM portends extremely poor prognosis and median overall survival of $<6$ months. While in this case there was CSF infiltration which would portend even poorer prognosis but she succumbed to sepsis due to Lower respiratory tract infection. CNS disease in MM can be effectively palliated especially because of relative radio sensitivity of MM due to which early responses are seen at lesser doses and an early diagnosis can improve quality of life effectively.

\section{References}

1. Kyle RA, Rajkumar SV (2004) Multiple myeloma. New England journal of medicine 351: 1860-1873.

2. Chou $T$ (2005) Multiple myeloma-recent advances in diagnosis and treatment. Gan to kagaku ryoho 32(3): 304-308.
3. Schluterman KO, Fassas AB, Van Hemert RL, Harik SI (2004) Multiple myeloma invasion of the central nervous system. Archives of neurology 61(9): 1423-1429.

4. Fassas $\mathrm{AB}$, Muwalla F, Berryman $\mathrm{T}$, Benramdane R, Joseph L, et al. (2002) Myeloma of the central nervous system: association with high-risk chromosomal abnormalities, plasmablastic morphology and extramedullary manifestations. British journal of haematology 117(1):103-108.

5. Gangatharan SA, Carney DA, Prince HM, Wolf MM, Januszewicz EH, et al. (2011) Emergence of central nervous system myeloma in the era of novel agents. Hematological oncology 30(4): 170-174.

6. Gozzetti A, Cerase A, Lotti F, Rossi D, Palumbo A, et al. (2012) Extramedullary intracranial localization of multiple myeloma and treatment with novel agents: a retrospective survey of 50 patients. Cancer 118(6): 1574-1584.
(C) (1) This work is licensed under Creative

To Submit Your Article Click Here: Submit Article

DOI: $10.32474 /$ OAJOM.2018.02.000128

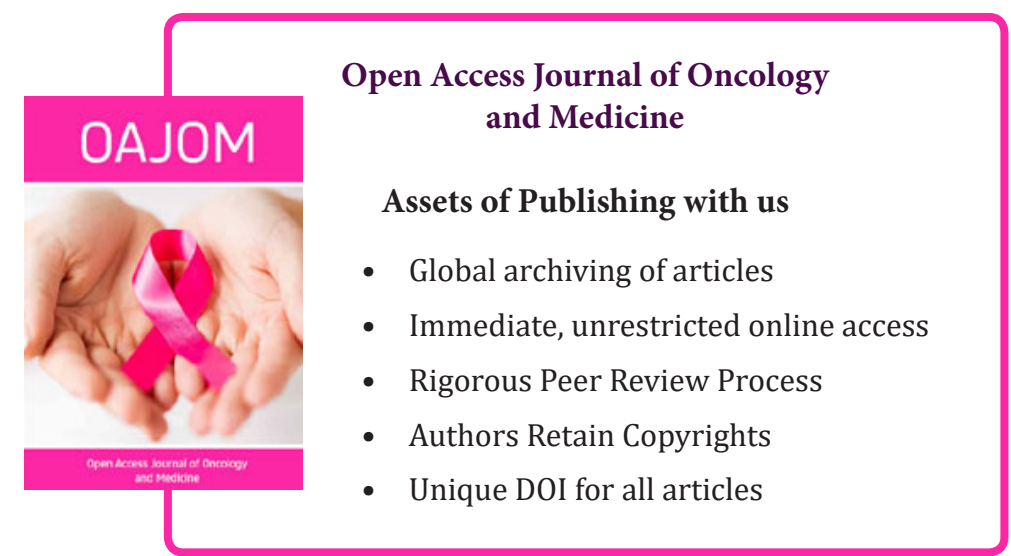

